\title{
Assessment of different agents for stabilization of a clay soil
}

\author{
A. R. Estabragh \\ Professor of Geotechnical Engineering, Faculty of Soil and Water Engineering, \\ University of Tehran, PO BOX 4411 Karaj 31587-77871, Iran \\ ORCID: $\underline{0000-0003-4545-2310}$ \\ Tel: +98 2632241119 \\ Fax: +982632226181 \\ Email: raeesi@ut.ac.ir \\ Corresponding Author: A.R. Estabragh
}

\section{A. Jahani}

Postgraduate Student, Faculty of Soil and Water Engineering, University of Tehran, PO BOX 4411 Karaj 31587-77871, Iran

Tel: +98 2632241119

Fax: +982632226181

Email: amir.jahani73@ut.ac.ir

\section{A. A. Javadi}

Professor of Geotechnical Engineering, Computational Geomechanics Group, Department of Engineering, University of Exeter, Exeter, Devon, EX4 4QF, UK

Tel: +44 1392723640

Fax: +44 1392217965

Email: A.A.Javadi@exeter.ac.uk

\section{M.Babalar}

Research Assistant, Faculty of Soil and Water Engineering, University of Tehran, PO BOX 4411 Karaj 31587-77871, Iran

Tel: +982612241119

Fax: +982612226181

Email: babalar@ut.ac.ir 


\title{
Assessment of different agents for stabilization of a clay soil
}

\begin{abstract}
Effects of different agents on stabilization of a clay soil were investigated through a series of laboratory experiments. The selected agents were cement, Ground Granulated Blast Furnace Slag (GGBS), mixture of GGBS and MgO (Magnesia) (GGBS:MgO) and mixture of GGBS, $\mathrm{MgO}$ and cement (GGBS:MgO:Cement). Mixtures of GGBS:MgO and GGBS:MgO:Cement were prepared at ratios of 3:1 and 3.0:0.5:0.5 by weight respectively. 5, 10 and $15 \%$ of these agents were mixed with soil samples. Atterberg limits and standard compaction tests were conducted on the mixtures. Also, unconfined compressive strength (UCS) tests were performed on compacted samples from the natural soil and the above mixtures at curing times of 7, 14 and 28 days. The results showed that all the used agents cause increase in the strength of the samples and the amount of increase is dependent on the percent of the agents and the curing time. It was revealed that the activation of GGBS with $\mathrm{MgO}$ and $\mathrm{MgO}$ :Cement is effective in increasing the strength in comparison with GGBS alone. Based on the scanning electron microscopy (SEM) results, it was found that the increase in strength of stabilized soil is resulted from bonding between soil particles and stabilizing agents.

Key words: clay soil, cement, GGBS, MgO, stabilization
\end{abstract}




\section{Introduction}

Soft soils commonly have high compressibility, excessive settlement and low shear strength properties (Shang et al., 2004). In engineering practice, strength, volume change and permeability are the three main aspects of soil behavior that may be improved. Soil stabilization, in its general meaning, considers every physical, physico-chemical and chemical method employed to make a soil suitable for its required engineering purpose. In road engineering, soil stabilization is used to improve the soil by using agents in order to use it as base or sub base courses and carry the expected traffic and pavement loads. There are many in situ methods for stabilization and improving the behavior of soft soils. Therefore, soil stabilization is a collective term for any physical, chemical or biological method that is used to improve the desired physical and mechanical properties of soil for civil engineering projects (Winterkorn, 1975). Since the load of any structure including road is transferred to the earth through its foundation, it is a problem when the subgrade of road is constructed on unsuitable soil and it should be improved before construction of the road. Therefore, when a soil is used in a civil engineering project such as road construction, it should be resistant to large deformations due to the repeated or continuous loading.

Soil stabilization can improve the behavior of soil as foundation material or as borrow area material for construction in civil engineering projects such as roads, embankments and dams. The methods of stabilization can be divided into mechanical methods, chemical methods or combination of mechanical and chemical methods. Random reinforcement of soils with natural or synthetic fibers, carpet waste fibers or tire buffing is a mechanical technique for improving the behavior (e.g., strength and load bearing 
capacity) of soils, in particular granular soils. Karabash and Cabalar (2015), Kutanaei and Choobbasti (2016) and Janalizadeh Choobbasti and Soleimani Kutanaei (2017) studied the effects of a specific percent of cement on the behavior of a randomly reinforced granular soil (a combination of mechanical and chemical methods) and found that it is effective in increasing the mechanical properties of the soil. Choobbasti and Kutanaei (2017), Choobasti et al. (2018) and Choobasti et al. (2019) conducted a set of experimental tests and found that adding nanosilica to the mixture of sand and cement improved the behavior of the soil. Cabalar and Karabash (2015) studied the use of crushed rock mixed with tire buffings and cement as sub-base materials for road construction. Cabalar and Karabash (2019) used gypsum, lime, calcite and Portland cement for stabilizing sand. They conducted triaxial tests on samples of a soil and reported that the degree of improvement in the soil behavior was dependent on the type of the used agent. In chemical methods for soil stabilization, the mechanical properties of soil can be improved by addition of chemical stabilizers such as lime, cement or fly ash. These chemical materials form flocculated structure in clay soil and make a cementitious bond between the particles that result in improvement of the behavior of soil. Cement has been used successfully as a stabilizing agent for a long time. However, the production of cement requires a significant amount of energy and also during its production a large amount of $\mathrm{CO}_{2}$ is emitted to the environment. To address these shortcomings, in recent years many researchers have examined the use of other stabilizing materials to replace the cement. The use of GGBS and $\mathrm{MgO}$ has been suggested for soil stabilization as replacement for cement. GGBS is produced in iron production industry (Higgins, 2007). During the process of iron production, the blast-furnace is rapidly quenched by water and 
the glassy granular materials with similar appearance to sand are generated. The cementitious behavior of these materials is excellent. They are grounded to the particle size similar to Portland cement and used as stabilizing material. The use of GGBS increases the durability including high resistance to chloride penetration and sulfate attack (Higgins, 2005). GGBS should be chemically activated so that the rate of its hydration is increased which results in the production of compounds such as CSH (Calcium Silicate Hydrate), CAH (Calcium Aluminate Hydrate) or CASH (Calcium Aluminate Silicate Hydrate) (Shi et al., 2006). Lime or cement is a common activator that is used with GGBS for stabilization of soil (Higgins, 2005 and Nidzam and Kinuthia, 2010). Yi et al. (2015) used $\mathrm{NaOH}, \mathrm{Na}_{2} \mathrm{CO}_{3}$, Carbide Slag (CS) and combination of $\mathrm{Na}_{2} \mathrm{SO}_{4}$ and $\mathrm{CS}$ as activators with GGBS for stabilization of a marine soft clay. They concluded that the mixture of $\mathrm{CS}$ and $\mathrm{Na}_{2} \mathrm{SO}_{4}$ as activator of GGBS yields higher strength than cement. Yi et al. (2014) studied the effect of lime as an activator for stabilization of marine clay. They found that the combination of lime and GGBS yields a higher strength than soil stabilized with Portland cement. Jin et al. (2015) used two types of commercial $\mathrm{MgO}$ as activator with GGBS and they concluded, based on the unconfined strength, that $\mathrm{MgO}$ is more effective than hydrated lime in activation of GGBS. Jegandan et al. (2010) carried out a study on the effect of GGBS with activators such as cement kiln duct, magnesia and zeolite for stabilization a soil in comparison with cement. They reported that these materials have many advantages over cement in stabilization of soil. Wild et al. (1999) and Celik and Nalbantoglu (2013) stated that combination of GGBS and Portland cement or lime is very effective in reducing the expansion of stabilized soil in the presence of sulfates or sulfides. 
Harrison (2001) proposed $\mathrm{MgO}$ as a replacement of cement for stabilization of soil. $\mathrm{MgO}$ is produced from heating of $\mathrm{MgCO}_{3}$ at temperature of $700-800^{\circ} \mathrm{C}$; hence the amount of energy consumed in production of $\mathrm{MgO}$ is lower than cement. The release of $\mathrm{CO}_{2}$ during its production is also lower than cement. Furthermore, when it is used as stabilizer it adsorbs $\mathrm{CO}_{2}$. Therefore, all these factors make $\mathrm{MgO}$ an effective replacement for cement (Harrison, 2001, Al-Tabba, 2013 and Olajire, 2013). MgO can be used alone or with activators such as cement or lime for stabilization of soil (Liska et al., 2008 and Liska and Al-Tabba, 2009). Jegandan et al. (2010), and Yi et al. (2014) found that the combination of $\mathrm{MgO}$ and GGBS in the ratio of 1: 9 by weight provides higher strength than mixture of lime: GGBS for stabilization of sand and clayey silty soils. They also reported that using mixture of $\mathrm{MgO}$ and cement provides more resistance against sulfate and acid attack than the soil that is stabilized with cement.

A review of the literature shows that there is limited information on the effect of GGBS alone and with different activators. This paper describes an experimental investigation into the effects of GGBS alone, cement, and GGBS activated by $\mathrm{MgO}$ and cement on the engineering properties of a clay soil. The tests carried out included Atterberg limits, compaction, and UCS tests that were conducted on natural soil and soil that was stabilized with different percentages of the above agents at different curing times. In addition, SEM tests were conducted on a number of stabilized soil samples to observe the microstructure formed in the stabilized soil and study its effects.

Civil Engineering projects such as roads that are constructed on clay soil may be adversely affected by the behavior of the clay. The volume of clay may change due to the changes of its water content that could lead to heaving, cracking or failure of the 
pavement of the road or other structures. Therefore, such soils should be stabilized before construction the project on them to prevent from swelling or shrinkage and to increase the strength of the soil. The use of by-product materials such as GGBS for stabilization has environmental and economic advantages in comparison with other agents such as cement (Higgins, 2005). GGBS my not produce the desired treatment in the soil; however, it can be activated by other agents such as lime, cement or MgO (Celik and Nalbantoglu (2013), Yi et al. (2014) and Jin et al. (2015)). In this work, for the first time, the activation of GGBS was done by $\mathrm{MgO}$ and also by a mixture of $\mathrm{MgO}$ and cement with different weight percentages. The effects of cement, GGBS alone and GGBS with activators on the engineering properties of a clay soil were studied in order to determine the reaction products of the stabilized materials and the mechanisms by which the engineering properties of clay soil are improved.

\section{Materials}

The materials that were used in this work were soil, cement, GGBS and MgO.

Soil

A clay soil was used for this work and it was acquired from a local supplier. According to the information provided by the supplier, it was obtained from around the Karaj city which is located $20 \mathrm{~km}$ west of Tehran at foothills of Alborz Mountains. Tables 1 and 2 show the physical, mechanical and chemical properties of the soil. The soil can be classified as clay with low plasticity (CL) according to the Unified Soil Classification System (USCS). XRD (X-ray diffraction) tests were conducted on samples of the soil and the results showed that the minerals of the soil include quartz, calcite, feldspar ( $\mathrm{Na}, \mathrm{Ca}$ ) 
and feldspar $(\mathrm{K})$. The results also showed that the clay minerals of the soil are Illite, Chlorite and Montmorillonite.

\section{Cement}

Portland Cement type 1 was used in this work. Its specific gravity and Blaine fineness were 3.15 and $4100 \mathrm{~cm}^{2} / \mathrm{g}$ respectively. Table 3 presents the physical and mechanical properties of the cement.

\section{$G G B S$}

The GGBS was supplied from Isfahan melting iron company in Iran. Its chemical composition, according to the information from the company, was $\mathrm{CaO}=41.5 \%, \mathrm{SiO}_{2}$ $=35.5 \%, \quad \mathrm{Al}_{2} \mathrm{O}_{3}=11.5 \%, \quad \mathrm{Fe}_{2} \mathrm{O}_{3}=0.5 \%, \quad \mathrm{MgO}=8.0 \%, \quad \mathrm{~K}_{2} \mathrm{O}=0.3 \%, \quad \mathrm{TiO}_{2}=0.4 \% \quad$ and $\mathrm{Na}_{2} \mathrm{O}=0.2 \%$. The mean size and specific surface of its particles were $50 \mu \mathrm{m}$ and 6-28 $\mathrm{m}^{2} / \mathrm{g}$ respectively.

$\mathrm{MgO}$

A commercial $\mathrm{MgO}$ was acquired from a local chemical supplier. It was composed of 94.2\% $\mathrm{MgO}, 1.7 \% \mathrm{CaO}, 0.85 \% \mathrm{SiO}_{2}, 0.62 \% \mathrm{Fe}_{2} \mathrm{O}_{3}$ and $0.16 \% \mathrm{Al}_{2} \mathrm{O}_{3}$. The specific gravity, specific surface and mean size of its particles were $3.55,250-300 \mathrm{~m}^{2} / \mathrm{g}$ and 60 $\mu \mathrm{m}$ respectively.

\section{Sample preparation}

Samples of natural soil and soil with cement, GGBS, mixture of GGBS: MgO and mixture GGBS: MgO: cement were prepared. The ratios of 3:1 and 3: 0.5:0.5 by weight were considered for combinations GGBS: $\mathrm{MgO}$ and GGBS: $\mathrm{MgO}$ : Cement respectively. The percent weights of 5, 10 and $15 \%$ of cement, GGBS or mixture of GGBS: MgO or GGBS: MgO: Cement (relative to the weight of air dry soil) were used in this work. The 
desired amounts of stabilizer were weighed and added to the air dry soil and mixed by hand. Standard compaction tests were conducted on the natural soil and the soil that was mixed with each of stabilizers, according to the ASTM D 698 (ASTM 2007) standard. The optimum water content and maximum dry unit weight were determined for each mixture from corresponding compaction curves.

Samples for UCS tests were prepared by static compaction for the natural soil and the mixture of soil with each of the stabilizers. The soil, desired stabilizer and water (according to the corresponding optimum water content) were weighted. First the soil and stabilizer were mixed, then water was added gradually to it and mixed thoroughly. The prepared mixtures were compacted by static compaction in a special stainless steel mould by using a loading machine. The compaction was done in three layers with loading rate of $1.5 \mathrm{~mm} / \mathrm{min}$ (the value of applied load to each layer was determined by trial and error before making the sample). The prepared samples with different stabilizers were stored in a curing cabinet according to the ASTM D1632 (ASTM 2007) standard for curing times of 7,14 and 28 days and the strength tests were then conducted on them.

\section{Experimental tests}

The laboratory tests including Atterberg limits, compaction and UCS tests were conducted on the natural soil and mixtures of soil with different percents of stabilizers according to the ASTM standards.

SEM tests were conducted on typical samples in order to observe the microstructure of the samples in different conditions. $10 \%$ of the prepared samples with different stabilizers with curing time of 7 days were chosen for the SEM tests. This test was performed following the procedure that was used by Tremblay et al. (2002). 


\section{Results}

Table 4 presents the results of the Atterberg limits and standard compaction tests for the natural soil and mixtures of soil with different percents of stabilizers. As shown in this table, the LL (Liquid limit), PL (Plastic limit) and PI (Plastic index) for the natural soil are 46,24 and $22 \%$ respectively. When $5 \%$ cement is added to the soil they are changed to 51,31 and $20 \%$ respectively. It shows that adding $5 \%$ cement causes increase in the values of Atterberg limits (LL and PL) in comparison with the natural soil. The results show that by increasing the percent of cement (to 10 and 15\%) the Atterberg limits are decreased in comparison with mixture of 5\% cement. Similar trends of variations in Atterberg limits are seen for the other stabilizers. Comparing the results of Atterberg limits for different stabilizers shows that at the same percent of stabilizers. The values of Atterberg limits for the soil that was stabilized with mixture of GGBS, MgO and cement are higher than those for the soil stabilized with mixture of GGBS and MgO. The results also showed that the Atterberg limits of soil stabilized with GGBS are more than the soilcement and less than the soil stabilized with mixture of GGBS and MgO.

As shown in this table (Table 4), the maximum dry unit weight and optimum water content for the natural soil are $17.7 \mathrm{kN} / \mathrm{m}^{3}$ and $17.5 \%$. For the mixture of soil with $5 \%$ cement these values are changed to $16.85 \mathrm{kN} / \mathrm{m}^{3}$ and $23.4 \%$ respectively. They show that adding 5\% cement decreases the maximum dry unit weight and increases the optimum water content. By increasing the percent of cement there is decrease in the values of both maximum dry unit weight and optimum water content in comparison with mixture of 5\% cement. A similar trend is also seen in this table for the other used stabilizers. 
Typical results of the soil stabilized with 5, 10 and 15\% cement at curing time of 14 days are shown in Fig.1. As shown in this figure, the failure of the natural soil occurred at axial stress of $420 \mathrm{kPa}$ and axial strain of $3 \%$ but for the soil stabilized with 5, 10 and $15 \%$ cement the failures stresses were $1464,2307.8$ and $4077.8 \mathrm{kPa}$ at strains of 2.6, 2.6 and $1.2 \%$ respectively. Fig. 2 presents typical results for the soil stabilized with 5\% GGBS at curing times of 7, 14 and 28 days. As shown in this figure the failure of the samples at 7, 14 and 28 days occurred at axial stresses of $1106.0 \mathrm{kPa}, 1419.7$ and $1891.7 \mathrm{kPa}$ at strains of $1.3,1.2$ and $1.0 \%$ respectively. Typical results for the soil stabilized with 5,10 and $15 \%$ mixture of GGBS and $\mathrm{MgO}$ for curing time of 7 days are presented at Fig.3. It is observed from this figure that the samples with 5, 10 and $15 \%$ stabilizer failed at 1123 , 1380 and $1886 \mathrm{kPa}$ at strains of 2.0, 1.5 and $1.3 \%$ respectively. Fig.4 presents the typical results for the soil stabilized with $10 \%$ stabilizer including GGBS, $\mathrm{MgO}$ and cement at curing times of 7, 14 and 28 days. It is seen from this figure that the failure of sample at curing times of 7, 14 and 28 days was at $1909.2,2592.7$ and $3157.6 \mathrm{kPa}$ at strain of 1.4, 1.2 and $0.85 \%$ respectively.

The microstructure of the natural soil and the soils with $10 \%$ of different stabilizers at curing time of 7 days was studied through SEM as shown in Fig.5. Fig.5a shows the SEM image of the natural soil that consists of different sizes of particles without any bonding between them. The SEM image of the soil with $10 \%$ cement at curing time of 7 days is presented in Fig.5b. As shown in this figure the spaces between particles are reduced in comparison with the natural soil and the soil particles are bonded to each other by hydration products of cement such as $\mathrm{CSH}$. These hydration products are needle or plate shape. Fig.5c shows the image for the soil stabilized with GGBS. The 
interconnection between the particles is not obvious in this figure and the space between the particles is relatively large. The microstructure of the soil stabilized with GGBS and $\mathrm{MgO}$ is presented in Fig.5d. This figure shows that brucite produced by hydration of $\mathrm{MgO}$ filled the pores between the particles which resulted in increase in the strength of the soil. Fig.5e presents the microstructure of the soil that was stabilized with GGBS:MgO:Cement. As shown in this figure, the mass of the soil shows a dense surface morphology and spaces between the particles are filled with hydration products of $\mathrm{MgO}$ and cement. The interconnection between particles is also made of these products which caused increase in the strength of the stabilized soil.

\section{Discussion}

The surface charges of clay particles are negative. These negative charges can attract cations and the positive charge side of water molecules from surrounding water (Budhu, 2000). This results in the formation of a film of water that is bonded to the surface of particles which is called adsorbed water. This layer of water contains cation and anions; the largest concentration of cations is at the surface of particles and it is decreased with distance away from the surface of particles until the concentration becomes that of normal water. The term diffused double layer (DDL) explains the negatively charged surface of particles and the dispersed layer of cations. The attraction and repulsion forces that act between the DDL of clay particles may lead to the formation of different structures of soil. The net force between particles influences the structure of the soil; the attractive or repulsive forces produce flocculated or dispersed structure in soil. Clay particles have the ability to exchange cations. The cations with higher positive valance in the soil water can be replaced with those with lower positive valance (Mitchell and Soga, 
2005). The cations that are attached to surface of clay particles are called exchange cations and they can be exchanged with other cations. This may result in change in the behavior of soil due to the changes in attractive or repulsive forces between particles. The total of exchange cations is called cation exchange capacity (CEC) and it is dependent on the particle size distribution, temperature and the exchange reaction environment (Mitchell and Soga, 2005).

The results in Table 4 show that when stabilizing agents are added to the soil, the LL and PL of the soil are increased in comparison with the natural soil. It can be said that when the stabilizers are added to the soil, the $\mathrm{pH}$ of pore fluid is increased which causes more additional negative charges on the edges of clay particles (Taylor, 1959). This leads to the attraction of clay particles in the form of edge to face attraction and results in a flocculated structure. The open structure in this form can hold more water that results in increase in the LL (Dash and Hussain, 2012). The results (Table 4) show that by increasing the percent of stabilizers the value of LL is decreased. This can be attributed to the reduction of the space between particles by increasing the degree of flocculation of the soil mass. It is seen from Table 4 that by adding stabilizers the value of PL is increased in comparison with the natural soil. This may be due to the change in the viscosity of pore fluid in comparison with natural water that causes increase in shear resistance of the interparticles and leads to increase in the plastic limit. As shown in this table, by increasing the percent of GGBS there is a reduction in the values of Atterberg limits. This is consistent with the results that were reported by Akinmurusu (1991) and Wild et al. (1996). Akinmurusu (1991) also studied the effect of GGBS on the consistency of a lateritic soil. The amount of used GGBS varied from 0 to $15 \%$ weight of 
soil. He observed a reduction in both LL and PL and an increase in the value of PI with increasing the GGBS content. These results are in agreement with the results that were reported by Wild et al. (1996).

Table 4 also shows the results of the compaction tests for the natural soil and the soil with different stabilizers at various percentages. As shown in this table, the maximum dry unit weight is decreased and optimum water content is increased by adding cement as the stabilizer. Similar results were reported by Estabragh et al. (2011 and 2016) who observed that by adding cement to a clay soil there is a reduction in maximum dry unit weight and increase in optimum water content. Adding cement to the soil causes a flocculated open structure in the mixture. The particles paste to each other with stronger bond than natural soil. Since the compaction has been done under constant energy, when this energy is used for mixture of soil and cement, it cannot destroy the bonds between particles like the natural soil. This results in reduction in the maximum dry unit weight. The results also show that the optimum water content of the soil is increased in comparison with the natural soil. This is due to the existence of more space between particles than in natural soil. A similar trend is also seen for other stabilizers that can be explained in the same way. It is seen from this table that for the stabilizers used, except for cement, by increasing the percent of stabilizers there is a reduction in the maximum dry unit weigh but there is no specific trend for the optimum water content. The results obtained for optimum water content are inconsistent with the results that were reported by Akinmurusu (1991) and Wild et al. (1996). Akinmurusu (1991) reported that the addition of GGBS to lateritic soil increases the optimum water content until $10 \%$ of GGBS and then there is a reduction in its value by increasing the percent of GGBS. Wild 
et al. (1996) indicated that overall, increasing the presence of GGBC causes increase in the value of optimum water content.

Figs. 6 and 7 show that using cement as stabilizer increases the strength of soil and the amount of increase is dependent on the percent of cement and curing time. On the other hand, by increasing the percent of cement or curing time the brittleness of the soil is increased (see Fig.1). Kézdi (1979) attributed these to the reaction that occurs by adding cement to soil. He stated that these reactions are: (i) hydration of cement that produces calcium hydroxide, (ii) adsorption of calcium hydroxide by the clay soil, and (iii) pozzolanic reactions that occur by saturation of the clay soil with calcium hydroxide between the particles. Therefore, the primary reaction includes formation of two silicate compounds $\mathrm{C}_{2} \mathrm{~S}$ (Dicalcium Silicate), $\mathrm{C}_{3} \mathrm{~S}$ (Tricalciun Silicate) and calcium hydroxide. They are deposited as separate crystalline solid phase such as torbermite gel. The cementitious particles are then formed that bond together and surround the soil particles forming a solid hardened skeleton. A higher percent of cement results in more cementation, which leads to greater strength of the mixture of soil cement (Estabragh et al., 2016). The secondary reaction is responsible for improving the hardening, strength and durability by increasing the bonds between the particles of soil that are effective in increasing the strength. In the second process, the silicates and aluminates originated from clay soil are dissolved by increasing the $\mathrm{pH}$ of solution due to existence of calcium hydroxide. These dissolved materials undergo a chemical reaction with calcium ions and produce additional cementitious materials. The produced materials such as $\mathrm{CAH}$ and CSH help to increase the strength of the soil (Estabragh et al., 2018). It is seen from Fig.2 that adding GGBS alone to the soil causes increase in the strength of the natural soil; $5 \%$ 
GGBS increases the strength of soil nearly three times of its initial strength. It is resulted from Figs. 6 and 7 that increasing the curing time and percent of GGBS also increases the strength of the soil. These results are not in agreement with the findings that were reported by Wild et al. (1998) who reported that there was no increase in the strength of kaolinite at curing times of 7 and 28 days when it was mixed only with GGBS as stabilizing agent. Oti et al. (2008a and 2008b) used lower Oxford clay (LOC) with GGBS and observed increase in strength which was attributed to the existence of gypsum. They argued that when gypsum in a clay soil is stabilized with GGBS, activation of the GGBS increases the strength of the soil. The results obtained in this work are consistent with results that were reported by Nidzam et al. (2010) who conducted a number of tests on clay soil stabilized with GGBS and observed increase in strength. They concluded that a cementation process similar to the cementation of clay soil and cement occurs that increases the strength of the soil. However, in the present work the increase of strength is observed by both increasing the curing time and increasing the percent of GGBS. The results show that at curing time of 7 days, the strength of the soil stabilized with $5 \%$ GGBS is more than that of the soil with $5 \%$ cement. It can be said that the hydration products of GGBS that are produced at this curing time are more crystalline than the hydration products of cement; and this causes increase in the strength of soil (Taylor, 1990). Caijun and Day (1993) studied the hydration process of GGBS when it is in contact to water. They reported that in this case a layer of liquid that includes Si-Al-O is formed on the surface of GGBS particles. Although this layer is able to adsorb the ions of $\mathrm{H}^{+}$that are produced from increasing the $\mathrm{OH}^{-}$, but it is not able to destroy the bonds between $\mathrm{Si}-\mathrm{O}$ and $\mathrm{Al}-\mathrm{O}$ to produce the $\mathrm{CSH}$ and $\mathrm{CAH}$ gel and increase the strength. The 
results of the present work show the opposite of the results that were reported by Caijun and Day (1993). It can be said the hydration of GGBS is dependent on many factors such as: chemical composition of GGBS, alkali concentration of reacting system, specific surface of GGBS and temperature (Kinuthia, 1997). Nidzam et al. (2010) reported that the initial reaction of GGBS during hydration produces a porous crystallized hydrated layer of coating of alumino-silicate products on the surface of GGBS particles within a short time of exposure to water. Richardson et al. (1994) stated that these coating surfaces are impermeable to water and prevent from further hydration reactions. Fig.5c also indicates that the arrangement of particles is different from Fig.5a. It is resulted that adding GGBS to soil causes rearrangement of particles and produces a new structure of soil mass due to hydration process. These actions change the initial structure of soil to a coagulated structure and create a condense structure. Nidzam et al. (2010) reported that the reaction between clay soil and GGBS can be a cementation process, similar to the cementation of clay soil with Portland cement. The cementation process takes place when the gel formed by hydration of activated GGBS coats and binds the particles and causes increase in the strength of soil that was stabilized with GGBS (Nidzam et al,:2010, Richardson et al.; 1994 and Taylor; 1990). Figs.3, 6 and 7 indicate that activation of GGBS with $\mathrm{MgO}$ increases the strength of the soil and the amount of increase is a function of curing time and percent of used mixture (GGBS:MgO). Yi et al. (2014) found from the results of their tests that GGBS alone has a slow hydration rate and its hydration is usually increased by using a chemical activator such as cement, lime or $\mathrm{MgO}$. The $\mathrm{MgO}$ is also hydrated when it has access to water and during this action it is changed to brucite. Brucite can react with water and $\mathrm{CO}_{2}$ and produce hydrated magnesium 
carbonate components such as nesquehonite, hydomagnesite and dypingite. Nesquehonite produces higher strengths than dypingite (Unluer and Al-Tabba, 2013). When hydration of GGBS and MgO occurs, they produce components of hydrated products (Liska, 2009). However as explained by Jin et al. (2015), in the blends of GGBS and MgO that was used as soil stabilizer, the first action is breakdown the GGBS bonds such as $\mathrm{Ca}-\mathrm{O}, \mathrm{Mg}-\mathrm{O}, \mathrm{Si}$ $\mathrm{O}-\mathrm{Si}$ and $\mathrm{Al}-\mathrm{O}-\mathrm{Si}$. After that ions of $\mathrm{Mg}$ react with $\mathrm{Si}-\mathrm{O}$ or $\mathrm{Al}-\mathrm{O}$ and form a gel. The produced gel pastes the particles to each other and fills the pore between the particles which increases the strength of the soil (Fig.5d). At 5\% of GGBS:MgO the strength of the stabilized soil is less than the soil stabilized with 5\% GGBS alone (Fig.7). As explained by $\mathrm{Yi}$ et al. (2014), the amount of $\mathrm{MgO}$ in 5\% of GGBS:MgO may not be sufficient to activate the GGBS to increase the final strength of the sample. On the other hand, if the amount of $\mathrm{MgO}$ is more in the mixture, it is likely that some unhydrated $\mathrm{MgO}$ may be left that can form cracks in the sample and lead to reduction of strength. Comparing the results of the tests using GGBS alone and GGBS with $\mathrm{MgO}$ shows that using GGBS:MgO at 10 and $15 \%$ is more effective than GGBS alone in increasing the strength. This may be due to the fact that the higher percent of this mixture results in a faster reaction and more hydrotalicite in the hydration products, and hence causes increase in the strength (Yi et al., 2014 and Jegandan et al., 2010). Gu et al. (2015) examined the effect of GGBS:MgO and GGBS:CaO on the stabilization of a clay soil and reported that the final strength of the soil stabilized with GGBS:MgO is more than GGBS:CaO. They attributed this to the relatively lower ratio of $\mathrm{Ca} / \mathrm{Si}$ in the $\mathrm{CSH}$ that is formed in GGBS:MgO that may give higher strength to the stabilized soil. On the other hand, they suggested that the activation of GGBS with $\mathrm{MgO}$ can induce hydrotalcite like 
phases which are more voluminous than $\mathrm{CSH}$ gel that had been found in lime that was used as GGBS activator (Jin et al. 2015). The gel produced by activation of GGBS with $\mathrm{MgO}$ may also fill the pores between particles and increase the density of the stabilized soil and cause increase in the strength of the soil. Consequently, the compressive strength of soil is increased with increasing the percent of $\mathrm{MgO}$.

The results of stabilized soil with different percents of GGBS:MgO:Cement are shown Figs. 4, 6 and 7. As shown in this figures, the amount of increase in the strength of the stabilized soil is dependent on the percent of used GGBS:MgO:Cement and curing time. Comparing the results (Figs.6 and 7) indicates that by using (GGBS:MgO:Cement), the obtained strength is more than GGBS:MgO particularly at 10 and $15 \%$ of these agent. In the case of soil stabilized with GGBS:MgO, the strength is less than the soil stabilized with cement, particularly at percents of 10 and $15 \%$. The hydration of the components that form the used agent is important in obtaining the strength of the soil. Cement can produce a relatively high $\mathrm{pH}$ in pore solution than $\mathrm{MgO}$. Therefore, the hydration of the stabilizing materials usually proceeds more quickly in the presence of cement than $\mathrm{MgO}$. The reaction of $\mathrm{MgO}$ with GGBS leads to the precipitation of a relatively dense layer of CSH gel (Gu et al., 2015). The produced gel is distributed less homogeneously in the soil matrix (Ben Haha et al., 2011). The existence of $\mathrm{MgO}$ causes reduction in the rate of cement hydration and the amount of CSH gel, increase in the uniformity of distribution of this gel and increase in the strength of the soil. Therefore, the hydration produces separate products and some of these products cause binding of the particles and some of them fill the spaces between the soil particles that are important in increasing the strength. Some of these products are made in the curing process as increasing the curing time cause 
increase in the strength. On the other hand, by increasing the percent of stabilizing agents, the strength is increased because more hydration products are produced increasing the strength of the soil.

The curing time affects the mechanical properties of stabilized soil. In this work only curing times of 7, 14 and 28 days were considered. It would have been useful to consider longer curing times such as 60 and 90 days as well. It would have been useful to study the effect of other ratios of activators (GGBS:MgO, GGBS:MgO:cement and cement only) on behavior of stabilized soil.

\section{Conclusion}

Stabilization of a clay soil was conducted by using different percents of cement and GGBS alone at different curing times. The stabilization of this soil was also examined by activation of GGBS with $\mathrm{MgO}$ and $\mathrm{MgO}$ :Cement and using the same percents and curing times. The results obtained from this work can be summarized as following:

1- The Atterberg limits of the soil that was stabilized with different agents are changed and the amount of change is dependent on the type and percent of the used stabilizer. The values of Atterberg limits for the soil that was stabilized with GGBS:MgO:Cement are more than the other used stabilizers.

2- Compaction parameters (optimum water content and maximum dry unit weight) are changed for the soil that was mixed with stabilizers and these variations depend on the type and percent of the used stabilizer. In general, the optimum water content increases and the maximum dry unit weight decreases in comparison with the natural soil. 
3- The strength of soil is increased by using the stabilizing agents and the amount of increase in strength is dependent on the type and percent of the used agent and the curing time. For different curing times, the effect of 5 and $10 \%$ GGBS:MgO:Cement in increasing the strength is more than the other used agents but for $15 \%$ of agent, cement is more effective than the rest of the agents.

4- All mixtures examined in this work are effective in stabilization of the soil. GGBS alone can increase the strength of soil but activation by $\mathrm{MgO}$ or mixture of $\mathrm{MgO}$ and cement is more effective in increasing the strength for different percents of the agents at various curing times. Mixture of $\mathrm{MgO}$ and cement is more effective than $\mathrm{MgO}$ in increasing strength, particularly at $15 \%$. 


\section{References}

Akinmurusu, J.O., 1991. Potential beneficial uses of steel slag wastes for civil engineering purposes. Resources Conservation and Recycling, 5 (1), 73-80.

Al-Tabba, A., 2013. Reactive magnesia cement. In Eco-efficient concrete, part 4, chapter 19. edited by Pacheco-Torgal, S. Jalali, J. Labrincha, and V.M. John, Woodhead Publishing Cambridge, UK.

ASTM, 2007. Annual book of ASTM standards, soil and rock. West Conshohocken, PA: American Society for testing Materials.

Ben Haha, M., Le Saout, G., Winnefeld, F., Lothenbach, B. 2011. Influence of activator type on hydration kinetics, hydrate assemblage and microstructural development of alkali activated blast-furance slag. Cement and Concrete Research, 41,301-310.

Budhu, M., 2000. Soil Mechanics and Foundations. John Wiley \& Sons, Inc., New York, USA.

Cabalar, A.F., Karabash, Z., 2015. California bearing ratio of a sub-base material modified with tire buffings and cement addition. Journal of Testing and Evaluation, 43(6), 1279-1287.

Cabalar, A.F., Karabash, Z., 2019. Influence of cement type and sample preparation on the small-strain behavior of sands. Arab Journal of Geoscience, Published on line, DOI: $10.1007 / \mathrm{s} 13369-019-04070-8$

Caijun, S., Day, R.L., 1993. Chemical activation of blended cements made with lime and natural pozzolans. Cement and Conrete research, 23 (6), 1389-1396. 
Celik, E., Nalbantoglu, Z., 2013. Effectts of ground blastfurnace slag (GGBS) on the swelling properties of lime-stabilized sulfate-bearing soils. Engineering Geology, 163, 20-25.

Choobasti, A.J., Samakoosh, M.A., Kutanaei,S.S., 2019. Mechanical properties soil stabilized with nano calcium carbonate and reinforced with carpet waste fibers. Construction and Building Materials. 211, 1094-1104.

Choobasti, A.J., Vafaei, A., Kutanaei,S.S., 2018. Static and cyclic triaxial behavior of cemented sand with nanosilica. Journal of Materials in Civil Engineering, 30 (10), 04018269

Choobasti, A.J., Kutanaei,S.S., 2017. Microstructure characteristics of cement-stabilized soil using nanosilica. Journal of Rock Mechanicas and Geotechnical Engineering, 9, 981-988,

Dash, S.K., Hussain, M., 2012. Lime stabilization of soils:Reappraisal. Journal of Materials in Civil Engineering, 24 (6), 707-714.

Estabragh, A.R., Beytolahpour, I., Javadi, A.A., 2011. Effect of resin on the strength of soil-cement mixture. Journal of Material in Civil Engineering ASCE, 23(7), 969-976.

Estabragh, A.R., Khatibi, M., Javadi, A.A., 2016. Effect of cement on treatment of a clay soil contaminated with glycerol. Journal of Material in Civil Engineering ASCE, 28(4), 4015157.

Estabragh, A.R., Kouchakjzadeh, M., Javadi, A.A., 2018. Impact of water and solution of glycerol on the treatment of sediment by cement. International Journal of Pavement Engineering, published online. 
Gu, K., Jin, F., Al-Tabba, A., Shi, B., Liu, C., Gao, L. 2015. Incorporation of reactive magnesia and quicklime in sustainable binders for soil stabilisation. Engineering Geology, 195, 53-62.

Janalizadeh Choobasti, A., Soleimani Kutanaei, S., 2017. Effect of fiber reinforcement on deformability properties of cemented sand. Journal of Adhesion Science and Technology, 31(14), 1576-1590.

Jegandan, S., Liska, M., Osman, A.A.-M., Al-Tabbaa, A., 2010. Sustainable binders for soil stabilization, Proceeding of the Institution of Civil Engineers, Ground Improvement, 163, 53-61.

Jin, F., Gu, K., Al-Tabbaa, A., 2015. Strength and hydration properties of reactive MgOactivated ground granulated blastfurnace slag paste. Cement \& Concrete composities. 57, 8-16.

Harrison, J., 2001. Reactive Magnesium Oxide Cements. International Patnt WO/2001/055049.

Higgins, D.D., 2007. Briefing: GGBS and sustainability. Proceeding of the Institution of Civil Engineers, Construction Materials, 160 (CM3), 99-101.

Higgins, D.D., 2005. GGBS and sustainability. Soil stabilization with ground granulated blast furnace slag, UK Cementitious Slag Makers Association report.

Karabash, Z., Cabalar, A.F., 2015. Effect of tire crumb and cement addition on triaxial shear behavior of sandy soils. Geomechanics and Engineering, 8(1), 1-15.

Kézdi, Á., 1979. Stabilized earth roads. Elsevier publisher

Kinuthia, J.M., 1997. Property changes and mechanisms in lime-stabilised kaolinite in the presence of metal sulphates. PhD thesis, University of Glamorgan, UK. 
Kutanaei, S.S., Choobasti, A.J., 2016. Triaxial behavior of fiber-reinforced cemented sand. Journal of Adhesion Science and Technology, 30(6), 579-593.

Liska, M., Vandeperre, L.J., Al-Tabbaa, A., 2008. Influence of carbonation on the properties of reactive magnesia cement-based pressed masonry units. Advances in Cement research, 20 (2), 53-64.

Liska, M., Al-Tabbaa, A., 2009. Ultra-green construction:reactive magnesia masonry products. Proceeding of the Institution of Civil Engineers, Waste and Resource Management, 162, 185-196.

Liska, M., 2009. Properties and applications of reactive magnesia cements in porous blocks. PhD thesis, University of Cambridge, Cambridge, UK.

Mitchell, J. K., Soga, K., 2005. Fundamentals of soil behavior ( $3^{\text {rd }}$ Ed). Hoboken: John Wiley \& Sons.

Nidzam, R.M., Kinuthia, J.M., 2010. Sustainable soil stabilization with blastfurnace slaga review. Proceeding of the Institution of Civil Engineers, Construction Materials, 163 (CM3), 157-165.

Olajire, A.A., 2013. A review of mineral carbonation technology in sequestration of $\mathrm{CO}_{2}$. Journal of Petroleum Science and Engineering, 109, 364-392.

Oti, J.E., Kinuthia, J.M., Bai, J., 2008a. Using slag for unfired clay masonry-bricks. Proceeding of the Institution of Civil Engineers, Construction Materials, 161 (4), 147-155.

Oti, J.E., Kinuthia, J.M., Bai, J., 2008b. Developing unfired stabilized building materials in the UK. Proceeding of the Institution of Civil Engineers, Engineering Sustainability, 161(4), 211-218. 
Richardson, I.G., Brough, A.R., Groves, G.W., Dobson, C.H., 1994. The characterization of hardened alkali-activated bastfurnace slag pastes and nature of the calcium hydrate (C-S-H) phase. Cement and Concrete Research, 24 (5), 813-829.

Shang, J.Q., Mohamedelhassan, E., Ismail, M., 2004. Electrochemical cementation of offshore calcareous soil. Canadian Geotechnical Journal, 41(5), 877-893

Shi, C., Krivenko, P.V., Roy, D., 2006. Alkali-activated cements and concretes. Taylor and Francis, London.

Taylor, A.W., 1959. Physico-chemical properties of soils-ion exchange phenomenon. Journal of Soil Mechanics and Foundations, Division, ASCE, 85 (2), 19-30

Taylor, H.F.W., 1990. Cement Chemistry. Academic Press, London

Tremblay, H., Duchesne, J., Locat, J., Leroueil, S., 2002. Influence of the nature of organic compounds on fire soil stabilization with cement. Canadian Geotechnical Journal, 39(3), 535-546

Unluer, C., Al-Tabbaa, A., 2013. Impact of hydrated magnesium carbonate additives on the carbonation of reactive $\mathrm{MgO}$ cements. Cement and Concrete Research, 54, 87-97.

Wild, S., Kinuthia, J.M., Robinson, R.B., Humphreys, I., 1996. Effects of ground granulated blastfurnace slag (GGBS) on the strength and swelling properties of lime stabilized kaolinite in the presence of sulphates. Clay Minerals, 31(3), pp.423-433.

Wild, S., Kinuthia, J.M.,Jones, G.I., Higgins, D.D., 1998. Effects of partial substitution of lime with ground granulated blastfurnace slag (ggbs) on the strength properties of lime stabilized sulphate bearing clay soils. Engineering Geology, 51(1), 37-53. 
Wild, S., Kinuthia, J.M., Jones, G.I., Higgins, D.D., 1999. Suppression of swelling associated with ettringite formation in lime stabilized sulphate bearing clay soils by partial substitution of lime with ground granulated blastfumace slag. Engineering Geology, 51(4), 257-277.

Winterkorn, H.P., 1975. Soil stabilization, Chapter in Foundation Engineering, Handbook, Winterkorn, H.F. and Fang, H.Y. (Eds). Van Norstrand Reinhold, New York.

Yi, Y. Gu, L. and Liu, S., 2015. Microstructural and Mechanical properties of limeactivated GGBS stabilized marine soft clay. Applied Clay Science, 103, 71-76.

Yi, Y., Liska, M., Al-Tabbaa, A., 2014. Properties and microstructure of GGBS-MgO pastes. Advances in Cement Research, 26 (2), 114-122. 
Table. 1. Physical and mechanical properties of soil

\begin{tabular}{|c|c|c|}
\hline Property & Standard Designation & Value \\
\hline Specific gravity, $\mathrm{G}_{\mathrm{s}}$ & ASTM D 854-10 & 2.65 \\
\hline \multicolumn{3}{|l|}{ Particle distribution } \\
\hline Gravel (\%) & & 0.0 \\
\hline Sand (\%) & & 27.0 \\
\hline Silt (\%) & & 33.0 \\
\hline Clay $(\%)$ & & 40.0 \\
\hline \multicolumn{3}{|l|}{ Consistency limits } \\
\hline Liquid limit, LL (\%) & ASTM D 4318-10 & 46.0 \\
\hline Plastic limit, PL (\%) & ASTM D 4318-10 & 24.0 \\
\hline Plastic index, PI (\%) & ASTM D 4318-10 & 22.0 \\
\hline Shrinkage limit, SL (\%) & ASTM D 427-04 & 13.0 \\
\hline USCS classification & ASTM D 2487-11 & $\mathrm{CL}$ \\
\hline \multicolumn{3}{|l|}{ Compaction characteristics } \\
\hline $\begin{array}{l}\text { Optimum water content, } w \\
(\%)\end{array}$ & \multirow[t]{2}{*}{ ASTM D 698-07e } & 17.5 \\
\hline $\begin{array}{l}\text { Maximum dry unit weight, } \\
\gamma_{\mathrm{dmax}}\left(\mathrm{kN} / \mathrm{m}^{3}\right)^{\mathrm{a}}\end{array}$ & & 17.70 \\
\hline
\end{tabular}

Table. 2. Chemical composition of soil

\begin{tabular}{|l|c|l|c|}
\hline $\begin{array}{l}\text { Chemical } \\
\text { component }\end{array}$ & Amount & $\begin{array}{l}\text { Chemical } \\
\text { component }\end{array}$ & Amount \\
\hline $\mathrm{pH}$ & 8.2 & $\mathrm{Cl}^{-}(\mathrm{meq} / \mathrm{L})$ & 26.2 \\
\hline $\mathrm{EC}^{\mathrm{a}}(\mathrm{dS} / \mathrm{m})$ & 5.03 & $\mathrm{HCO}_{3}(\mathrm{meq} / \mathrm{L})$ & 3.7 \\
\hline $\mathrm{Na}^{+}(\mathrm{meq} / \mathrm{L})$ & 42.0 & $\mathrm{SO}_{4}^{2-}(\mathrm{meq} / \mathrm{L})$ & 19.2 \\
\hline $\mathrm{Ca}^{2+}(\mathrm{meq} / \mathrm{L})$ & 46.0 & $\mathrm{CO}_{3} \mathrm{Ca}(\%)$ & 4.2 \\
\hline $\mathrm{Mg}^{2+}(\mathrm{meq} / \mathrm{L})$ & 2.2 & $\mathrm{O}^{-\mathrm{C}}{ }^{\mathrm{b}}(\%)$ & 0.2 \\
\hline
\end{tabular}

a- Electrical Conductivity

b- Organic content 
Table. 3. Properties of cement

\begin{tabular}{|l|c|c|}
\hline Properties & Standard designation & Value \\
\hline Normal consistency (\%) & ASTM C 187-10 & 25.5 \\
\hline Primary setting time (min) & ASTM C 191-08 & 160 \\
\hline Final setting time (min) & ASTM C 191-08 & 220 \\
\hline $\begin{array}{l}\text { Compressive strength } \\
\text { (MPa) } \\
\text { 7days }\end{array}$ & ASTM C 109-08 & 19.2 \\
\hline $\begin{array}{l}\text { Tensile strength (MPa) } \\
7 \text { days }\end{array}$ & ASTM C 190-85 & 2.7 \\
\hline $\begin{array}{l}\text { Flexure strength (MPa) } \\
7 \text { days }\end{array}$ & \\
\hline
\end{tabular}

Table. 4. Atterberg limits and compaction parameters for natural soil and soil stabilized with different percents of agents

\begin{tabular}{|l|l|l|l|l|l|l|l|l|l|}
\hline Soil & $\begin{array}{c}\text { C } \\
(\%)\end{array}$ & $\begin{array}{c}\text { G } \\
(\%)\end{array}$ & $\begin{array}{c}\text { G: } \\
\text { M (\%) }\end{array}$ & $\begin{array}{c}\text { G:M:C } \\
(\%)\end{array}$ & $\begin{array}{c}\text { LL } \\
(\%)\end{array}$ & $\begin{array}{c}\text { PL } \\
(\%)\end{array}$ & $\begin{array}{c}\text { PI } \\
(\%)\end{array}$ & $\begin{array}{c}\gamma_{\mathrm{dmax}} \\
\left(\mathrm{kN} / \mathrm{m}^{3}\right)\end{array}$ & $\begin{array}{c}w_{\text {opt }} \\
(\%)\end{array}$ \\
\hline 100 & 0 & 0 & 0 & 0 & 46 & 24 & 22.0 & 17.7 & 17.5 \\
\hline 95 & 5 & 0 & 0 & 0 & 51 & 31 & 20.0 & 16.85 & 23.4 \\
\hline 90 & 10 & 0 & 0 & 0 & 48 & 28 & 20.0 & 16.83 & 22.8 \\
\hline 85 & 15 & 0 & 0 & 0 & 45.5 & 26.5 & 19.0 & 16.81 & 22.6 \\
\hline 95 & 0 & 5 & 0 & 0 & 53 & 26 & 27.0 & 17.7 & 19.0 \\
\hline 90 & 0 & 10 & 0 & 0 & 50 & 24 & 26.0 & 17.0 & 19.8 \\
\hline 85 & 0 & 15 & 0 & 0 & 47 & 23 & 24.0 & 16.6 & 21.0 \\
\hline 95 & 0 & 0 & 5 & 0 & 54 & 28 & 26 & 16.4 & 22.6 \\
\hline 90 & 0 & 0 & 10 & 0 & 52 & 26 & 26 & 16.2 & $21 / 6$ \\
\hline 85 & 0 & 0 & 15 & 0 & 48 & 24 & 24 & 16.1 & 21.0 \\
\hline 95 & 0 & 0 & 0 & 5 & 55 & 30 & 25 & 16.64 & 22.1 \\
\hline 90 & 0 & 0 & 0 & 10 & 52 & 28 & 24 & 16.6 & 21.7 \\
\hline 85 & 0 & 0 & 0 & 15 & 49 & 25 & 24 & 16.45 & 20.6 \\
\hline
\end{tabular}

$\mathrm{G}=\mathrm{GGBS}, \mathrm{M}=\mathrm{MgO}, \mathrm{C}=\mathrm{Cement}$ 


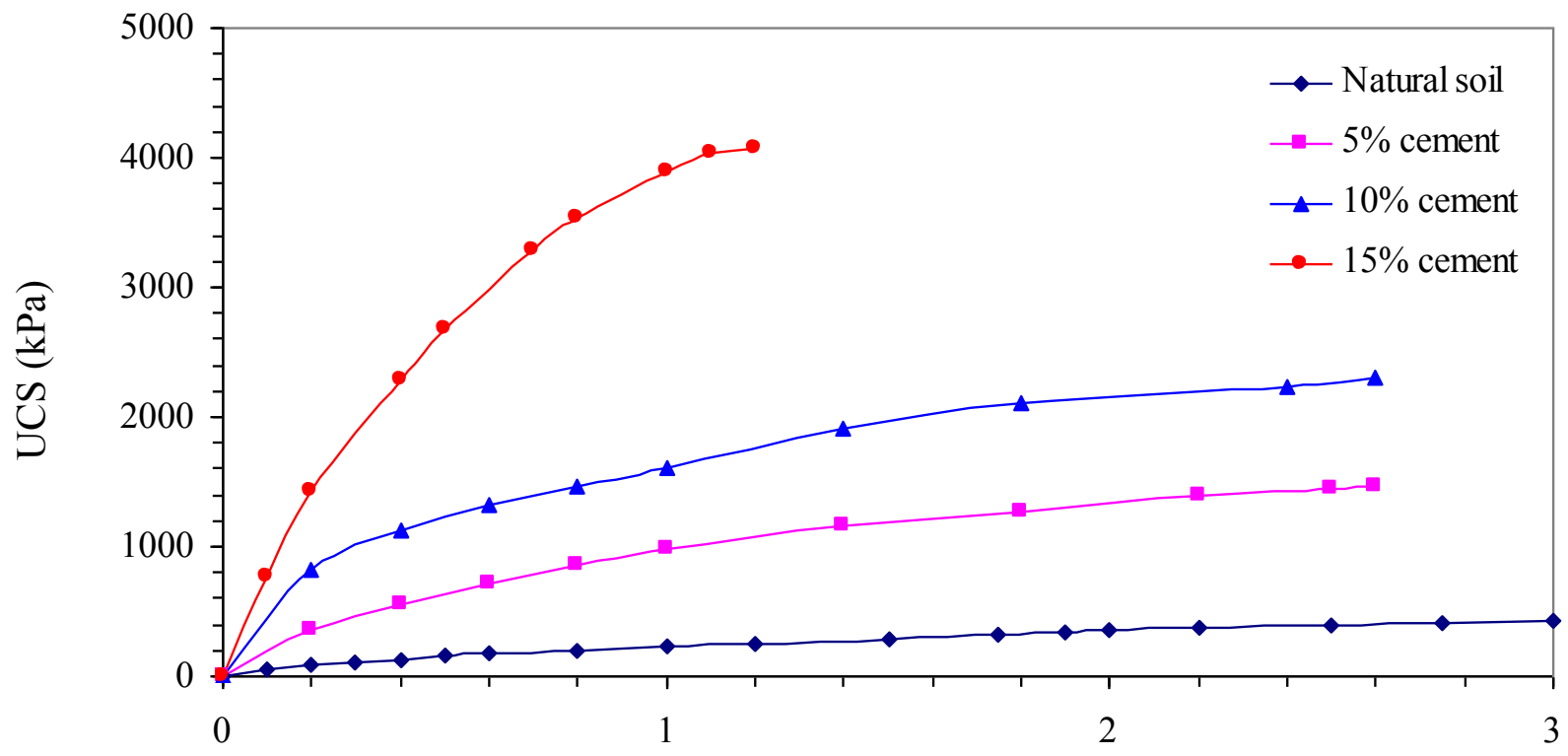

Axial strain, $\varepsilon_{\mathrm{a}}(\%)$

Fig.1. Stress-strain curves for natural soil and soil with different percents of cement at curing time of 14 days.

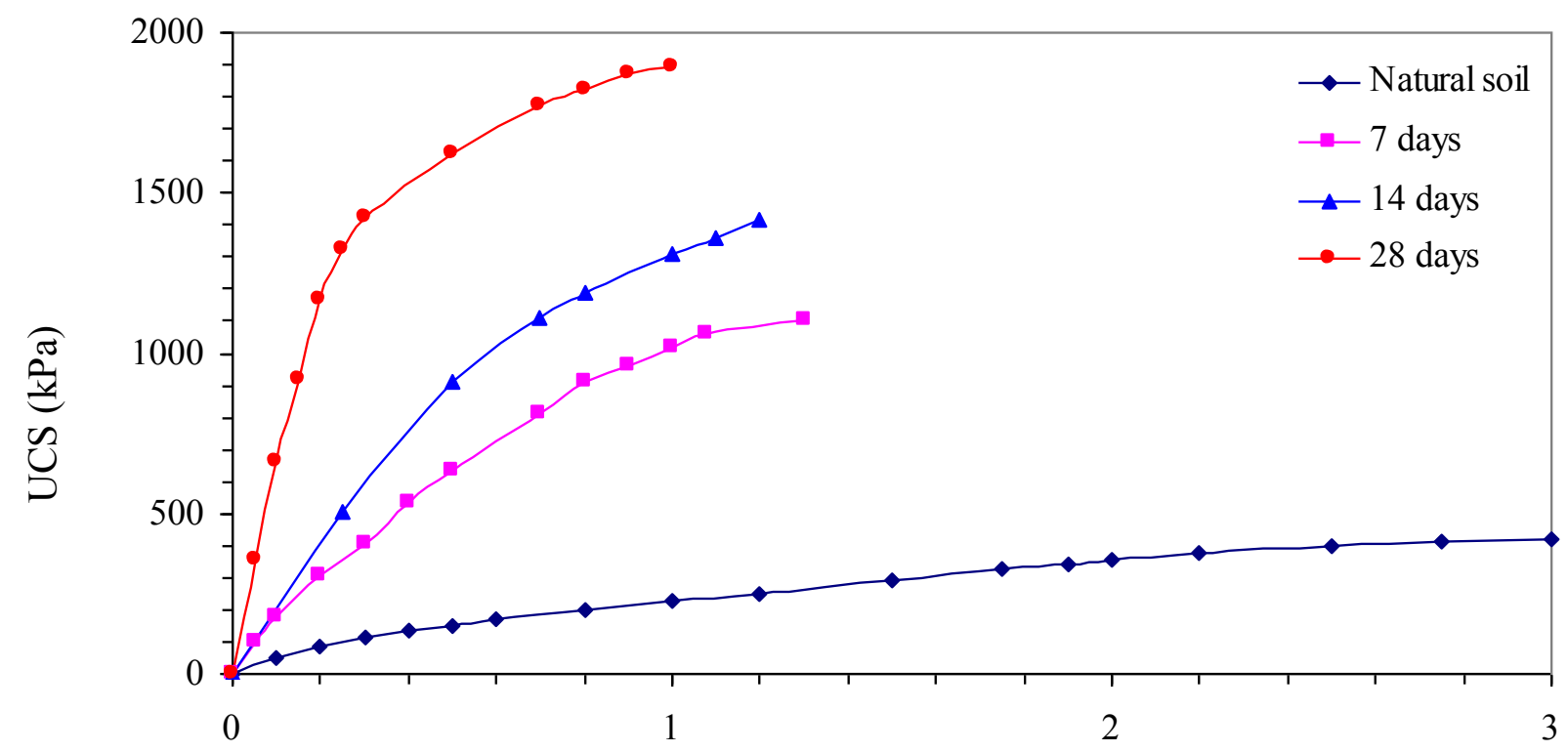

Axial strain, $\varepsilon_{\mathrm{a}}(\%)$

Fig.2. Stress-strain curves for natural soil and soil with 5\% GGBS at different curing times 


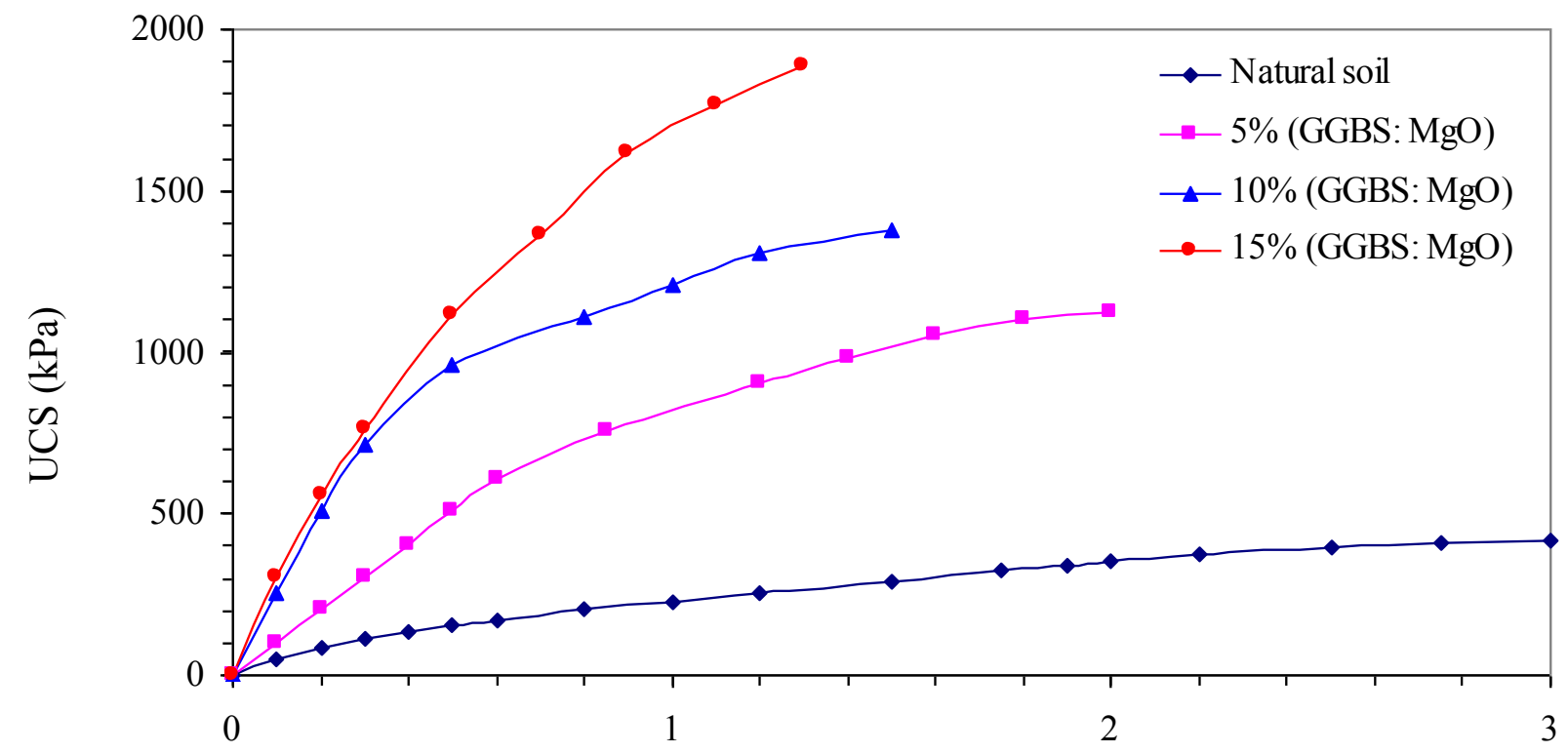

Axial strain, $\varepsilon_{\mathrm{a}}(\%)$

Fig.3. Stress-strain curves for natural soil and soil with different percents of GGBS: $\mathrm{MgO}$ at curing time of 7 days

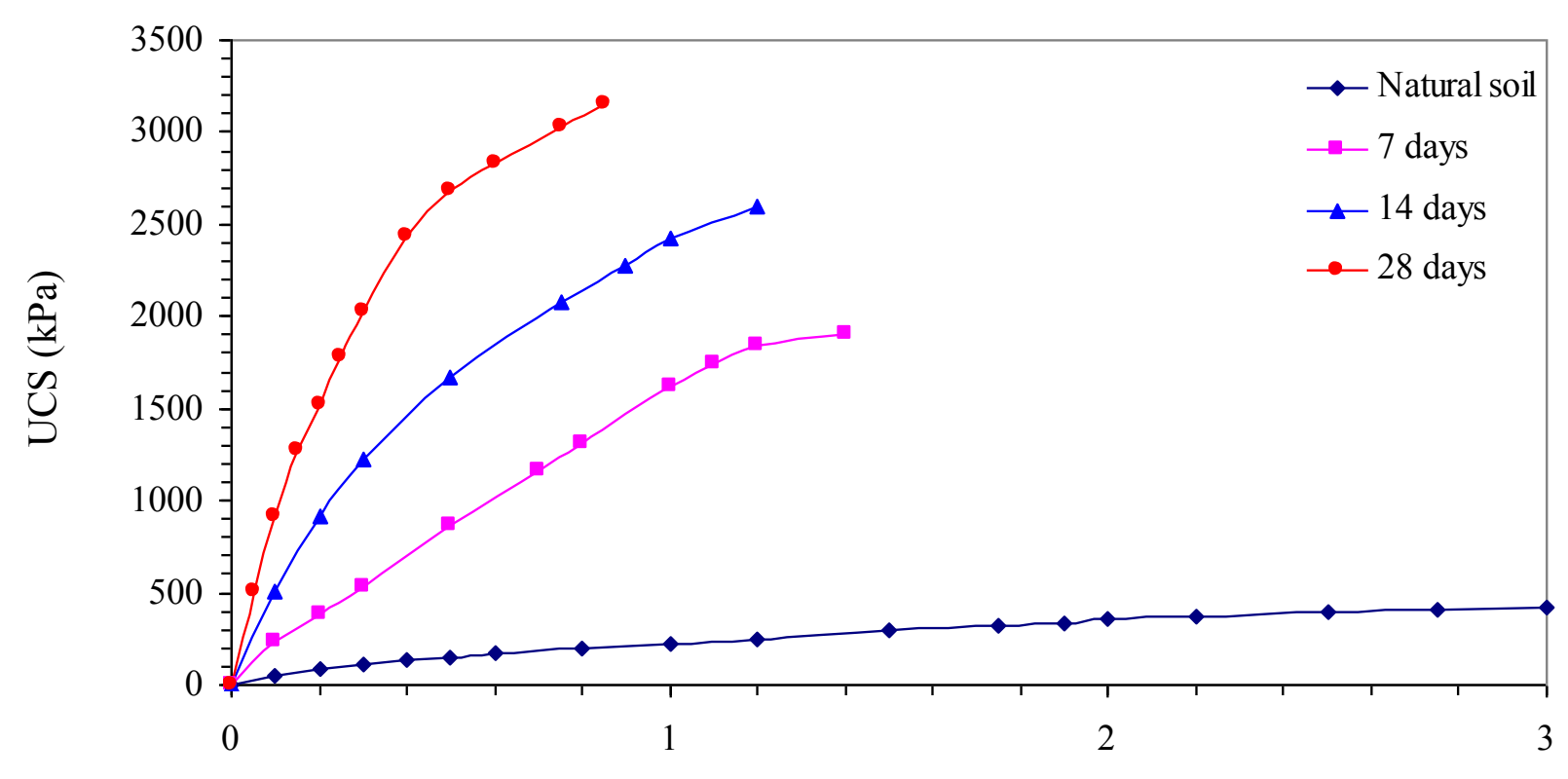

Axial strain, $\varepsilon_{a}(\%)$

Fig.4. Stress-strain curves for natural soil and soil with 10\% GGBS:MgO:Cement at different curing times 


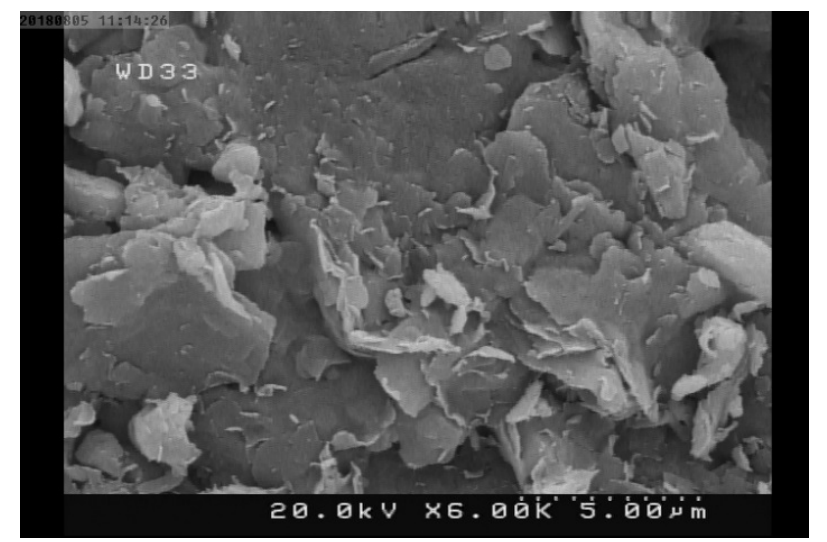

(a)

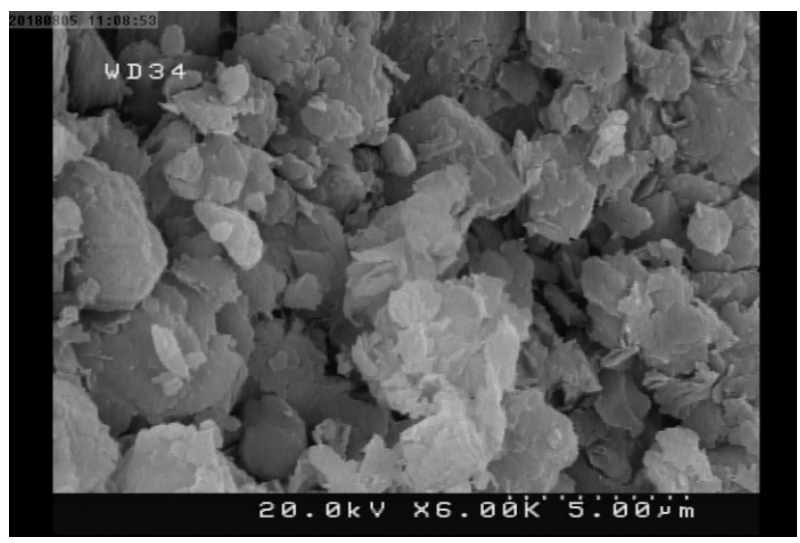

(c)

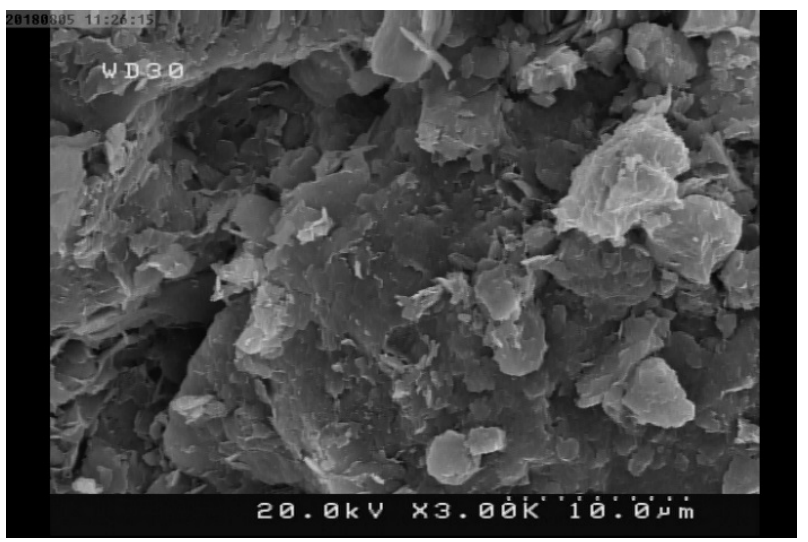

(b)

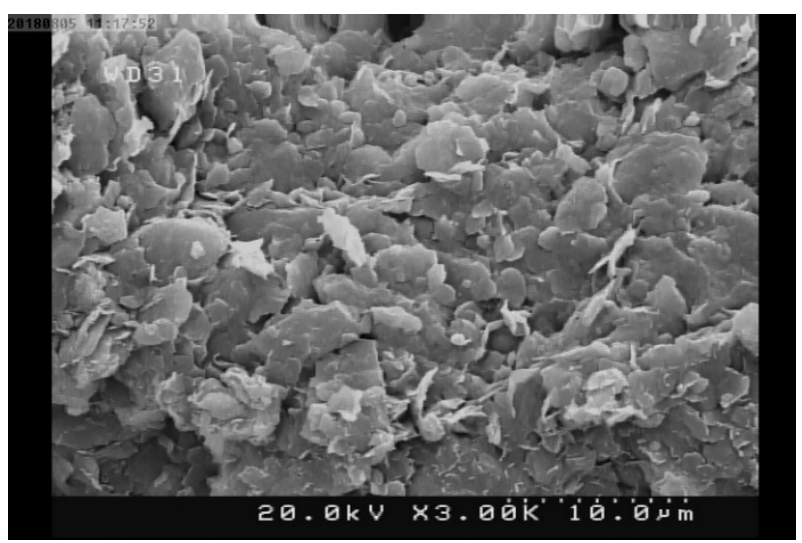

(d)

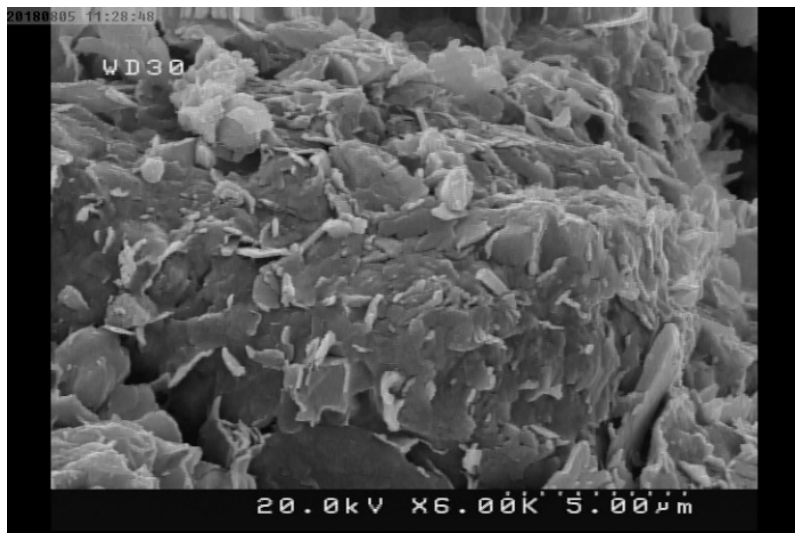

(d)

Fig.5. SEM images of (a) natural soil, (b) soil with cement (c) soil with GGBS (d) soil with GGBS: $\mathrm{MgO}$ (e) soil with GGBS: $\mathrm{MgO}$ : Cement at 7 days curing time 


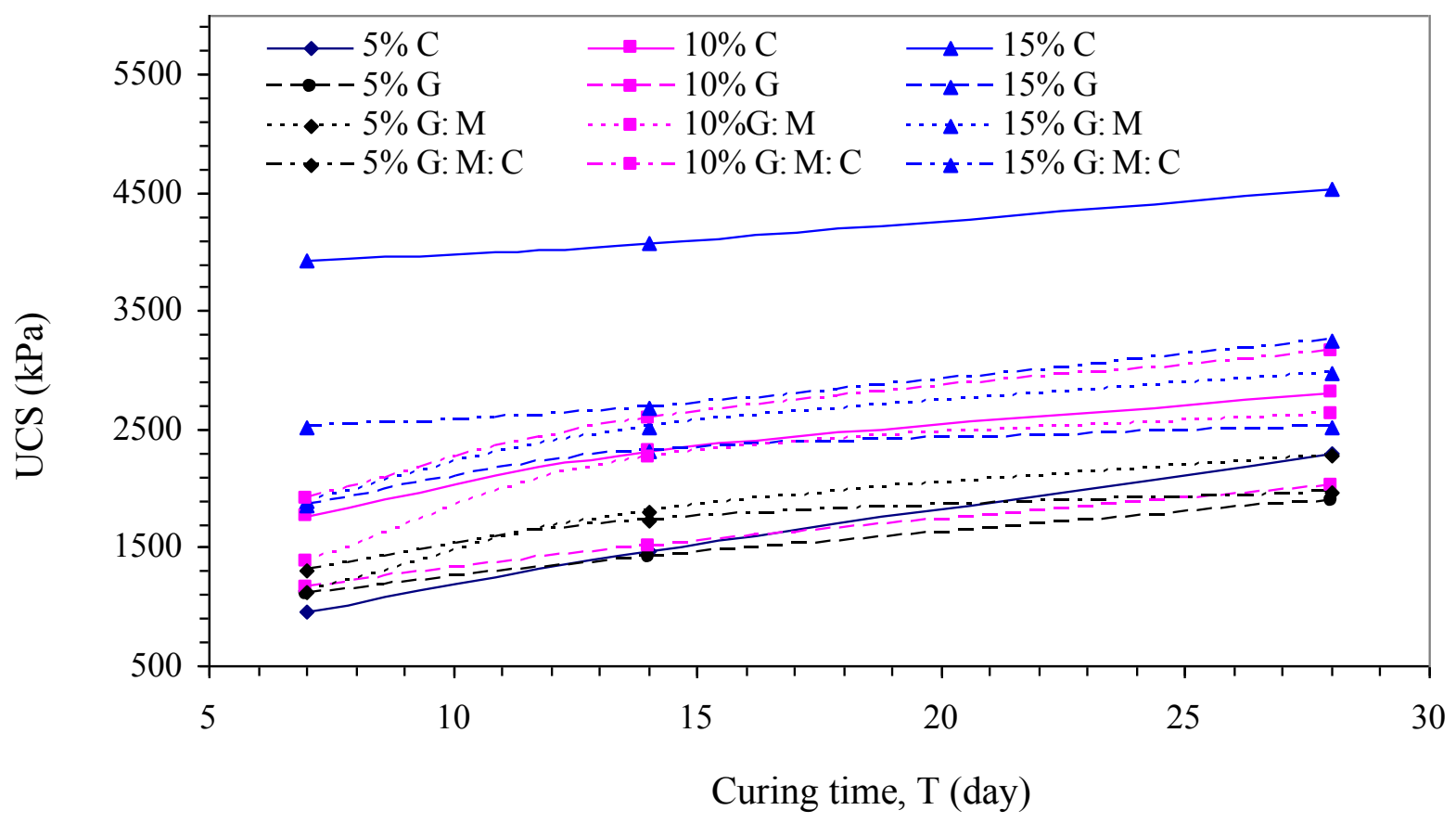

Fig.6. Variation of compressive strength with curing time for soil with cement, GGBS, GGBS: $\mathrm{MgO}$ and GGBS: $\mathrm{MgO}$ : Cement with different percentages $\mathrm{C}=$ Cement, $\mathrm{G}=\mathrm{GGBS}, \mathrm{M}=\mathrm{MgO}$ 


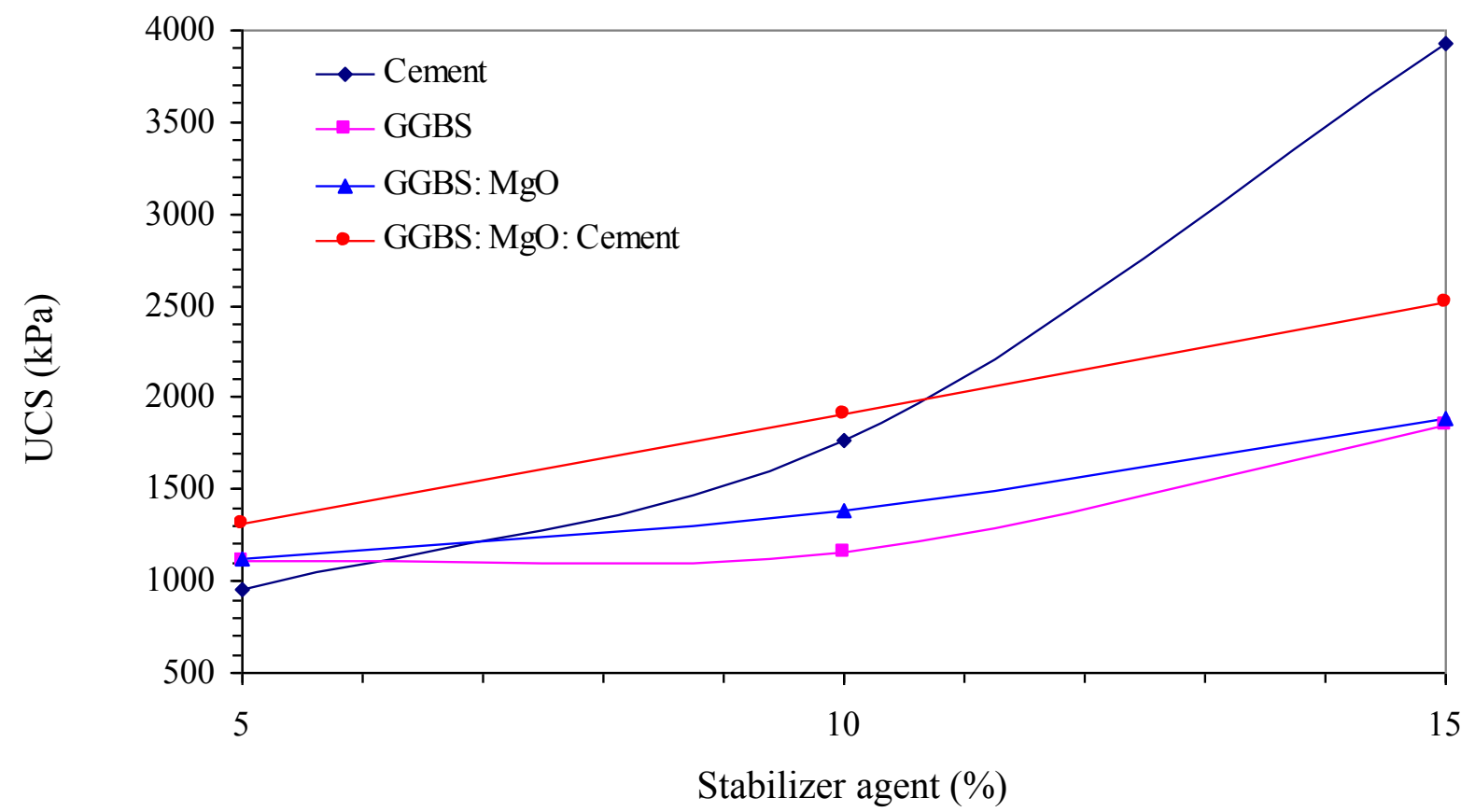

(a)

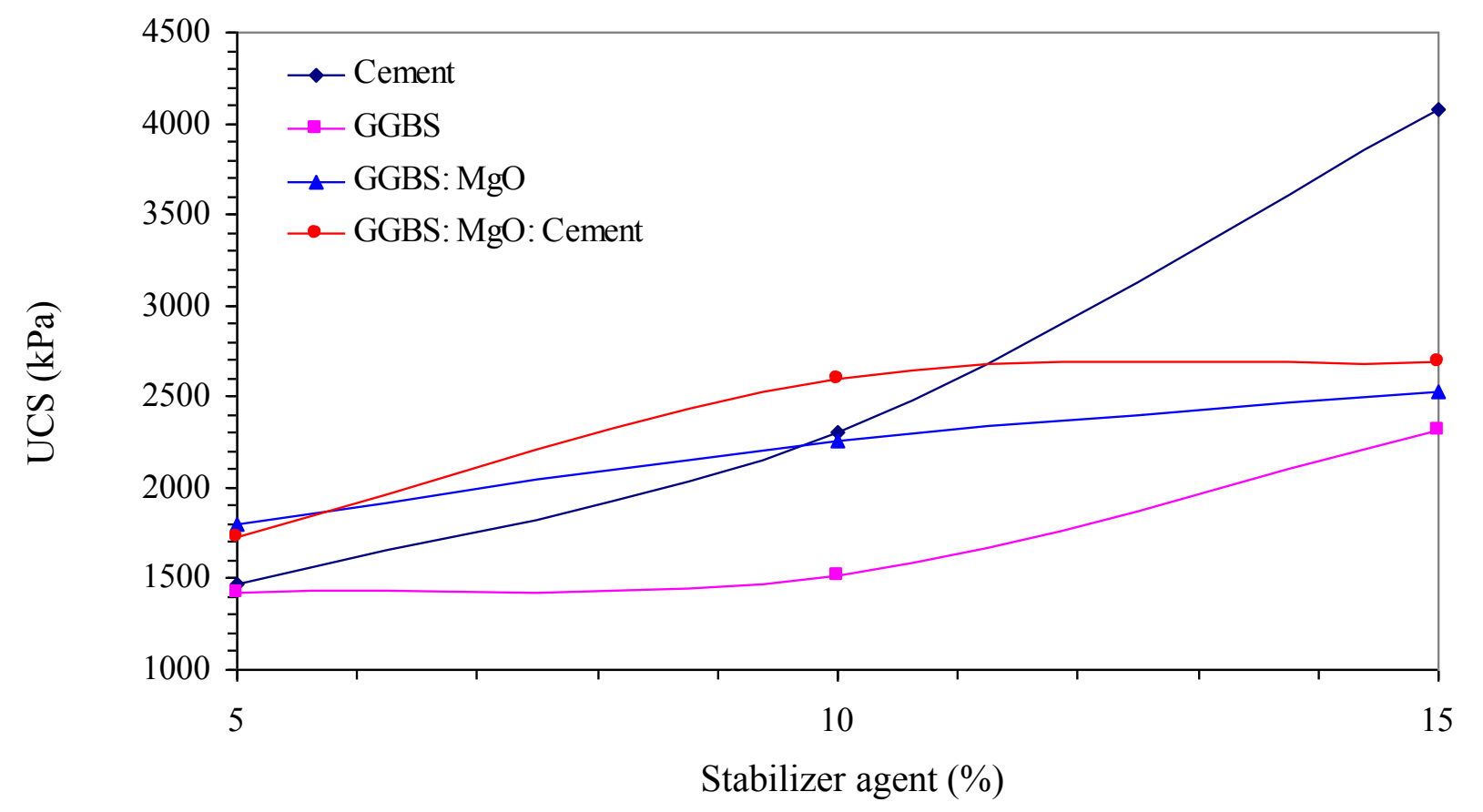

(b) 


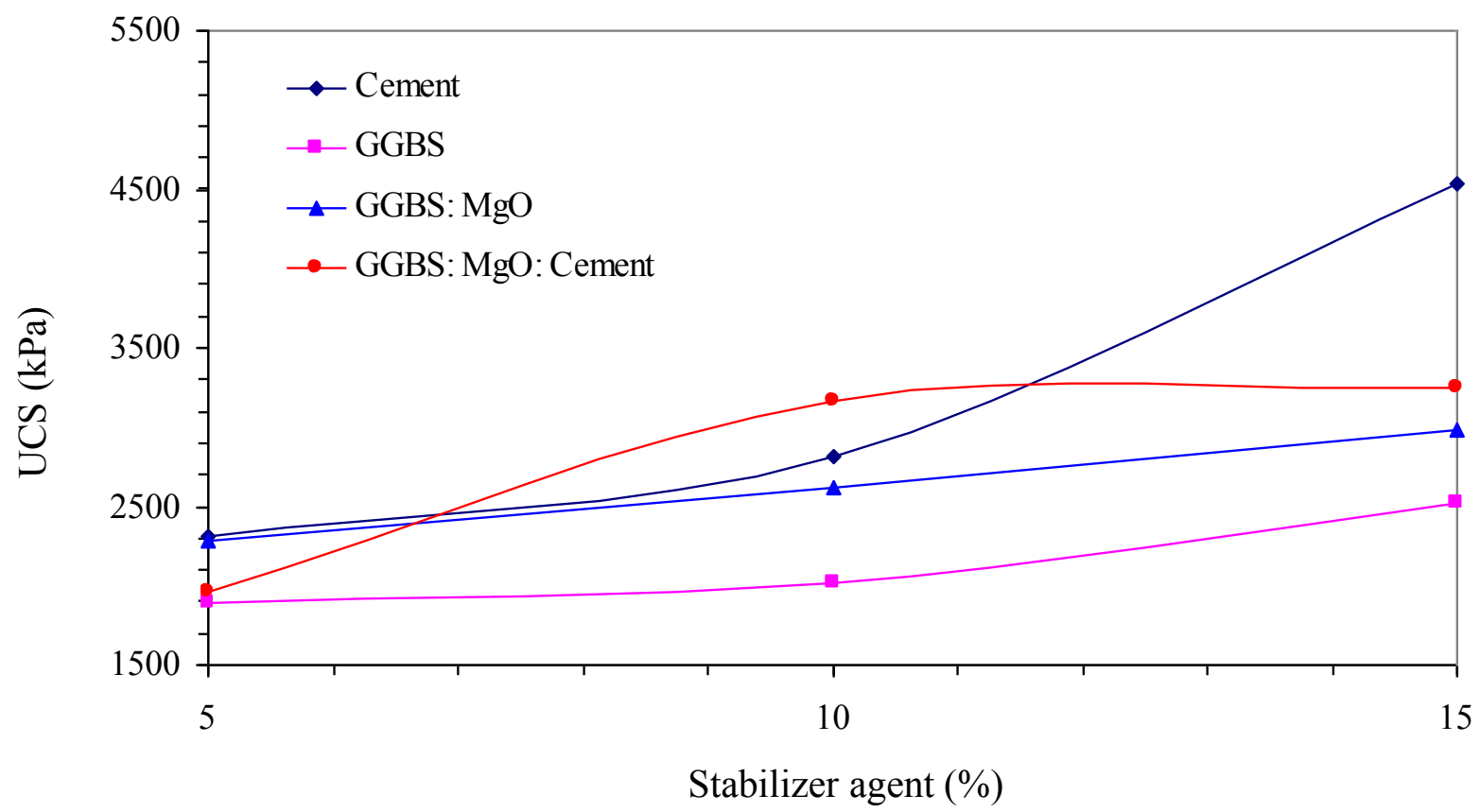

(c)

Fig.7. Variation of compressive strength with different percents of stabilizing agents for (a):7 days, (b): 14 days, (c ): 28 days curing times 